drainage is necessary, it should be carried out through a wide-bore tube with an under-water seal.

There is no doubt in my mind that our colleagues in Anaesthesia have, to a large extent, overcome these problems by the use of intermittent positive pressure ventilation. So much so, that fixation of a flail chest by mechanical devices is seldom indicated.

I have not touched on mediastinal haemorrhage-injuries to the heart, bronchi, thoracic duct, or diaphragm, but clearly these must be considered in assessing chest injuries.

Finally, I should remind you that in children the thoracic cage is so elastic that it is possible for severe compression of the chest contents to take place, without much in the way of external evidence of damage to the chest wall.

\title{
REFERENCES
}

Cheshire, D. J. E. \& Coats (I966). Int. F. Paraplegia, 4, I.

Clarke, R., Topley, E. \& Flean, C. T. G. (I955). Lancet, i, 629.

Clarke, R. \& Fisher, M. R. (1956). Br. F. clin. Pract. I0, 746.

\section{FREQUENCY AND DISTRIBUTION OF ASSOCIATED INJURIES IN TRAUMATIC PARAPLEGIA AND TETRAPLEGIA}

\author{
By F.-W. MEINECKE, M.D. \\ From the Spinal Centre of the Surgical Department of the Berufsgenossenschaftlichen \\ Krankenanstalten Bergmannsheil, Bochum, Germany
}

\section{INTRODUCTION}

TRAUMATIC paraplegia usually impresses laymen and doctors to a point where their whole attention is focussed on this condition. For the injured it means in most cases an acute danger of life which continues to exist for a shorter or longer span of time. The prominence of this condition quite often determines all further measures and may lead to neglecting or overlooking associated injuries. It is these associated injuries, however, which can be of great consequence, as they increase the danger to life. The lack of sensation due to paralysis often obscures the extent of the total injury and thus renders diagnosis more difficult. Also, paraplegia might require different methods in the treatment of the associated injuries than those normally applied in patients without injuries of the spinal cord. It is the subject of this paper to examine the following questions:

I. Is paraplegia often associated with other injuries?

2. Are there typical accidents resulting in paraplegia?

3. Are there typical associated injuries in specific accidents?

4. Are there types of associated injuries which occur with particular frequency to different parts of the body?

We shall not discuss any specific methods of treatment as this would exceed the subject of this paper. 


\section{MATERIAL}

Our spinal unit is part of the surgical department of a large accident hospital in the Ruhr Area, the greatest industrial area of Germany where coalmining and steel industry are predominant. Our hospital belongs to the accident insurance association for coal-miners (Bergbauberufsgenossenschaft). The majority of our cases are industrial accidents.

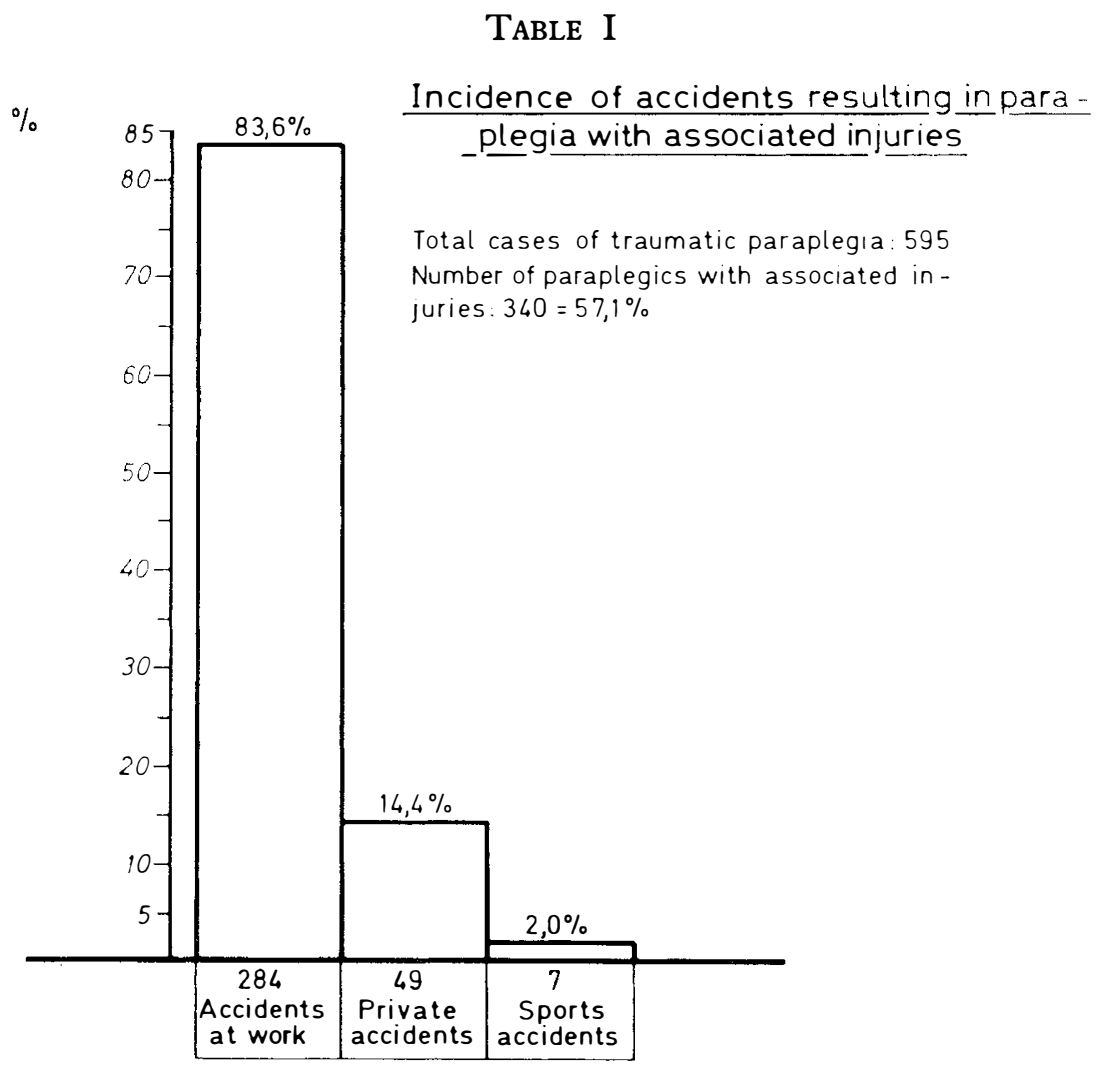

Since the end of the war we have treated altogether 615 patients with incomplete or complete paraplegia. Out of these cases, 20 were the results of diseases. Among the remaining 595 paraplegics, we found 340 who had additional injuries. This means that in more than in every second paraplegic (57. I per cent) we have to expect associated injuries; 83.6 per cent (284) of the above 340 patients were injured in accidents at work. Tables I and II show the incidence of the various types of accidents in the 340 cases. 'Traffic accidents' include accidents on the way to or back from work as well as private accidents. Under the heading 'miscellaneous accidents at work' (Table II) we have listed accidents which did not fit into any of the larger categories. 'Domestic accidents', too, include different types, for example attempted suicide. Due to coal-mining we have two large groups of patients: those 'buried by coal or stone' and those by 'falls'. There are 
strikingly few associated injuries in sports accidents; the total number of sports accidents is considerably larger, but those not listed had injuries to the vertebrae and spinal cord only.

TABLE II

\section{Type of accident}

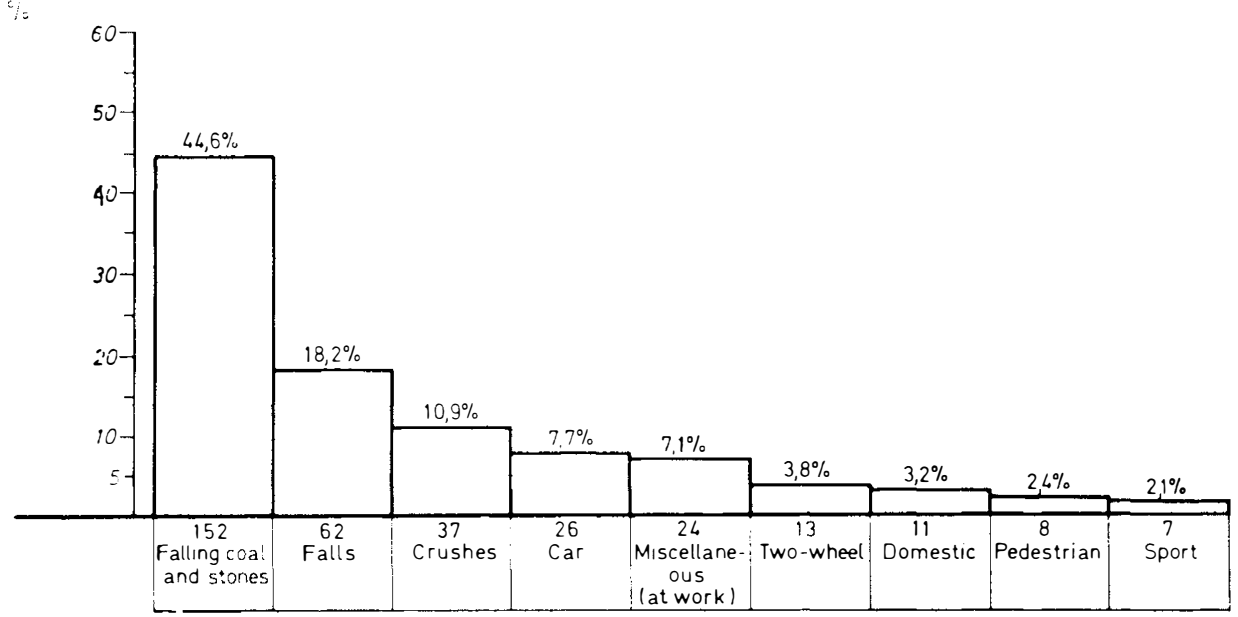

TABLE III

Incidence of injuries to the different parts of the body

$\%$

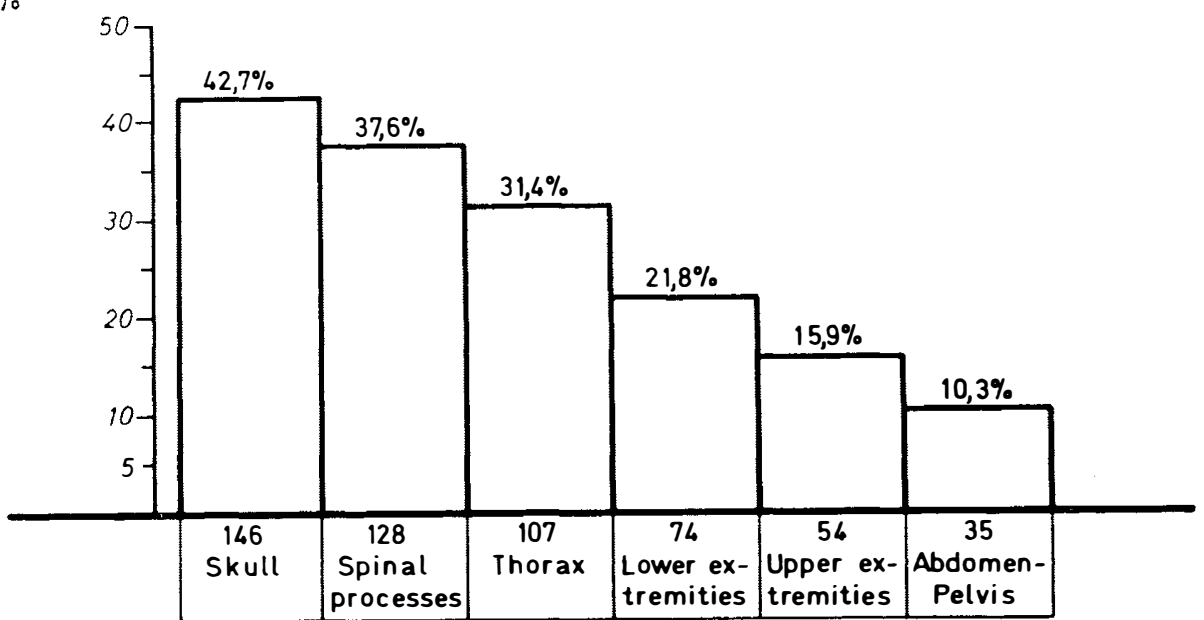

The Tables III to VIII show the frequency of injuries in the different parts of the body. However, as we are dealing with 'multiple injuries', the per cent. figures are not in accordance with the absolute figures. If, for example, head and chest injuries were combined in one patient, this case was listed as head as 
well as chest injury. The same applies later when we consider the different parts of the body.

Skull injuries (Table IV) are predominant in all associated injuries, whereas injuries to pelvis and abdomen occur only rarely. Out of 146 cases where the skull was affected, $68 \cdot 2$ per cent. suffered a concussion, as against only 4 per cent. who sustained a concussion without any distinct injuries to the head.
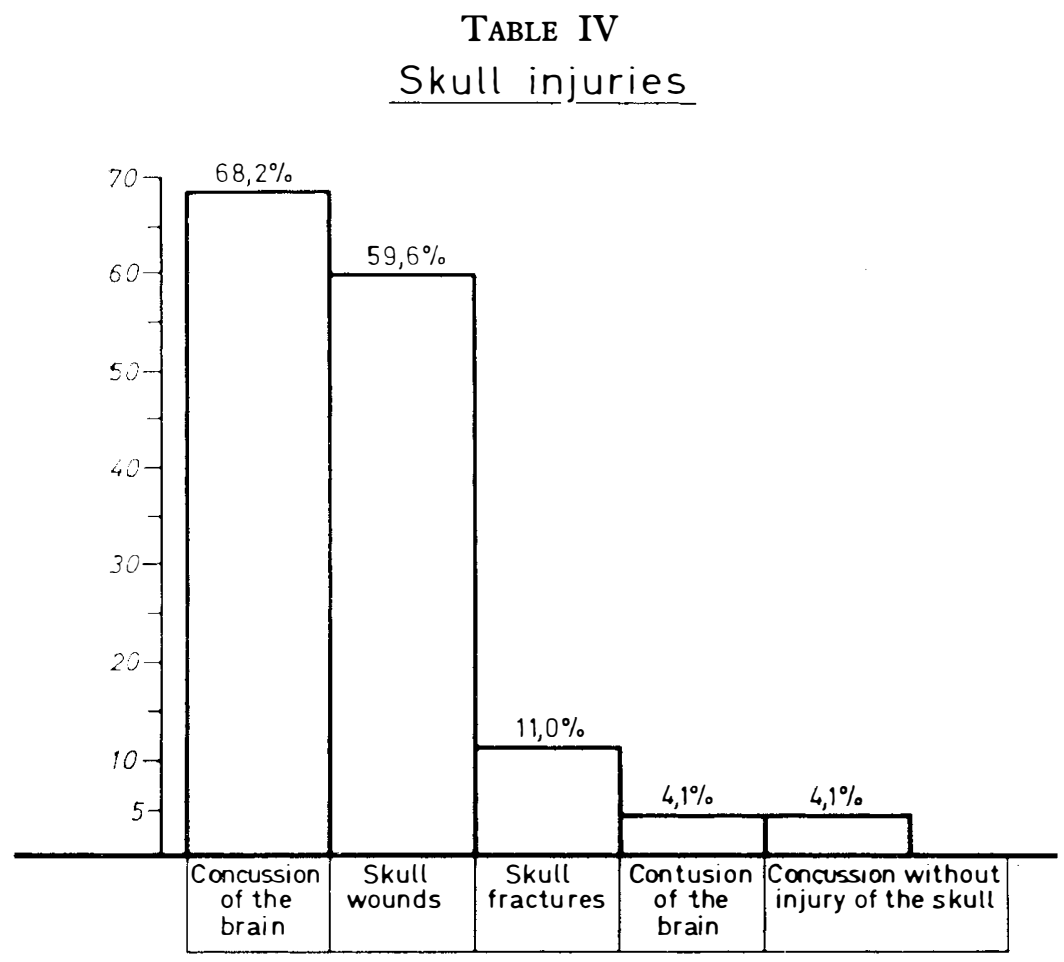

It is natural that injuries to the vertebrae are often accompanied by injuries to the transverse and spinous processes. This was true in I 28 cases. However, we need not expect any considerable complications to result from such a condition.

It is quite different with chest injuries. Here, 87.9 per cent., the majority of 107 cases, suffered fractures of the ribs. They were not seldom associated with a haemothorax and/or pneumothorax.

In the lower extremities, fractures of the leg were most frequent; they were found in $8 \mathrm{I} \cdot \mathrm{I}$ per cent. of all cases. These comprise isolated fractures of the tibia or fibula as well as 'leg fractures' in the classical sense of the term. Paraplegics should also be carefully examined for dislocations of joints.

We find similar conditions in the upper extremities where fractures of ulna and radius and classical forearm fractures together with very few hand fractures make up a total of 50 per cent. Fractures of the scapula (24.I per cent.) and of the clavicula $(\mathbf{2 2} \cdot \mathbf{2}$ per cent.) are not seldom overlooked. They are often associated with chest injuries. 
Injuries to the internal organs of the abdomen are rare considering the total figure of associated injuries. Two stomach and one spleen rupture were produced by gunshot injuries. Two bladder injuries were caused by contusion of the abdomen with the bladder probably filled at the time of accident.

Now the question arises whether typical associated injuries are caused by specific types of accidents. In Tables IX and X we have to take into consideration that total figures of 24 cases and less only have a limited statistical value. This is

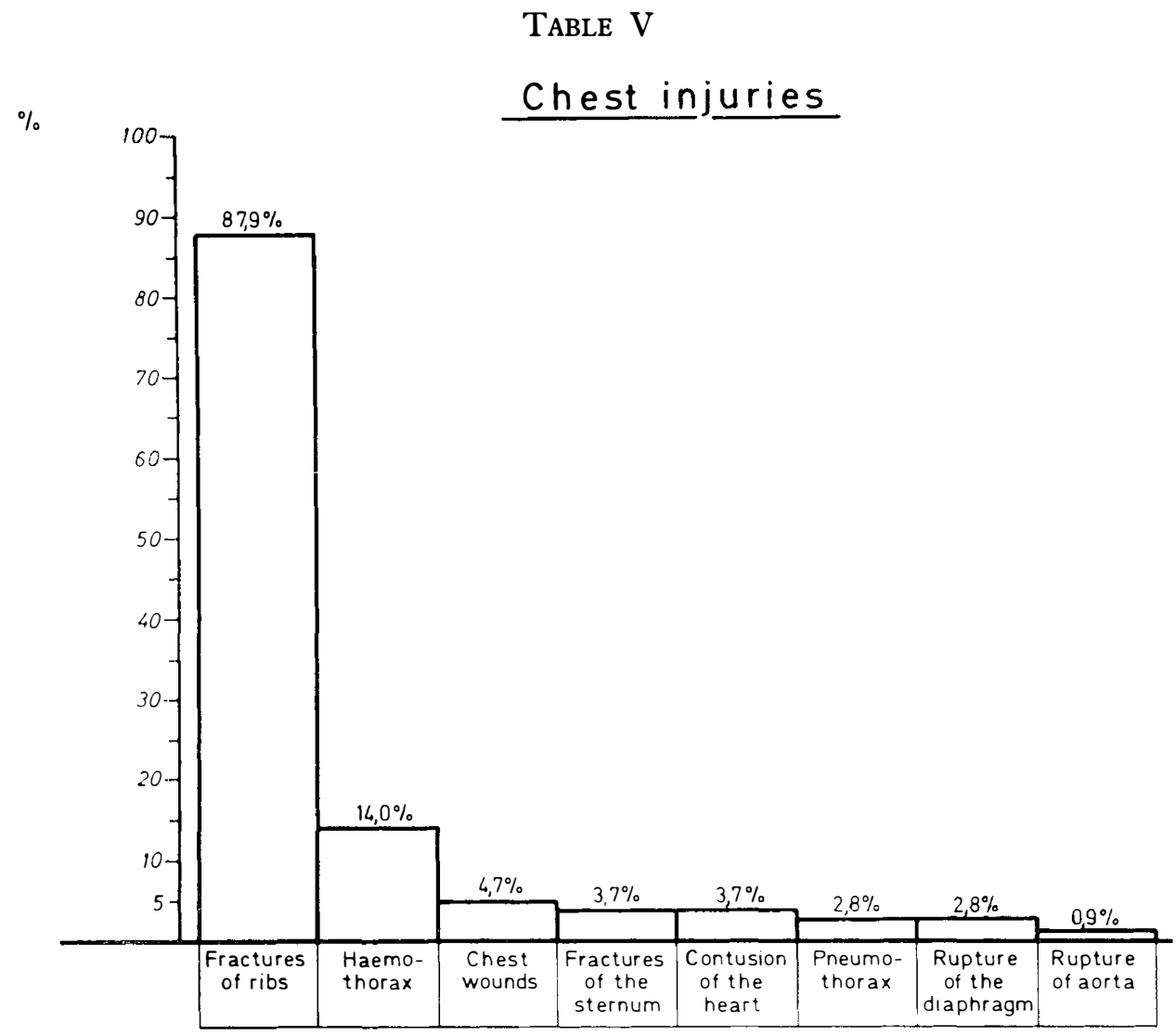

true of the last six columns. We have nevertheless taken these groups into account in order to present an overall picture. In injuries produced by falling coal or stone, fractures of the vertebral processes are predominant; in crushes they are about as frequent as injuries to the thorax; in all other groups it was the head which was affected most frequently. In pedestrians and sportsmen we found no arm injuries and in the latter group no injuries to the lower limbs or to the pelvic and abdominal region.

We finally want to show to what degree the spinal cord was affected. In all types of injury-excepting sports-the dorso-lumbar junction was affected with particular frequency. It dominates in accidents at work. Sports accidents caused only cervical lesion. Complete paraplegia predominated in all groups. 
PAPERS READ AT THE I 967 SCIENTIFIC MEETING

TABLE VI

$\%$

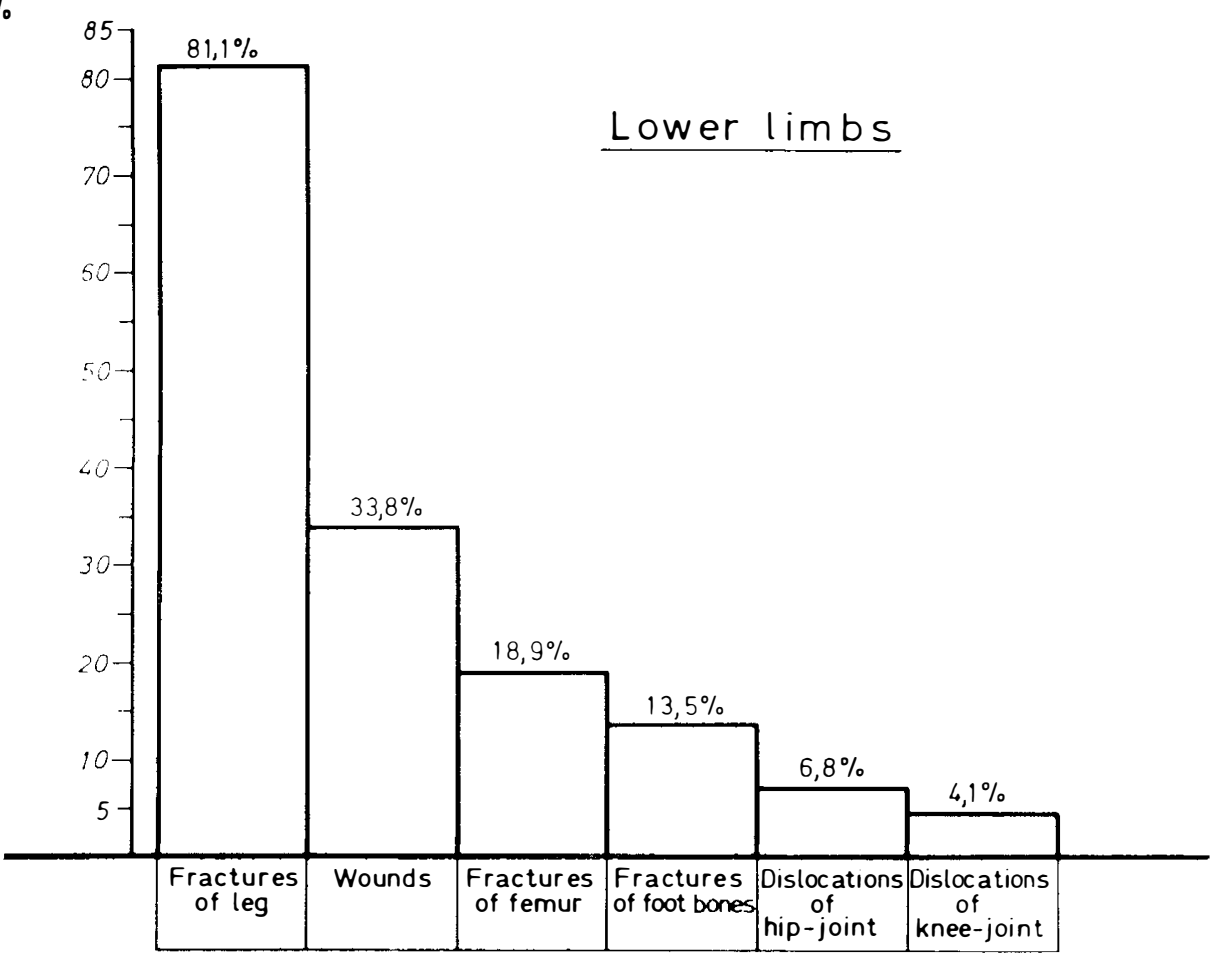

TABLE VII

Upper limbs

$\%$

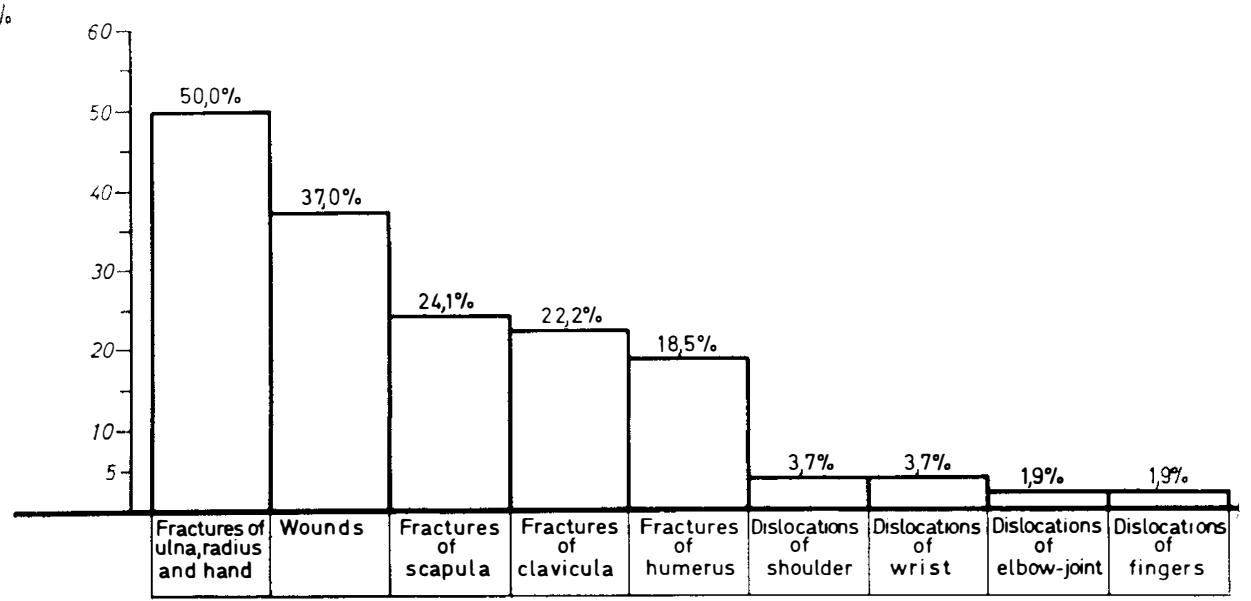




\section{Injuries to pelvis and abdomen}

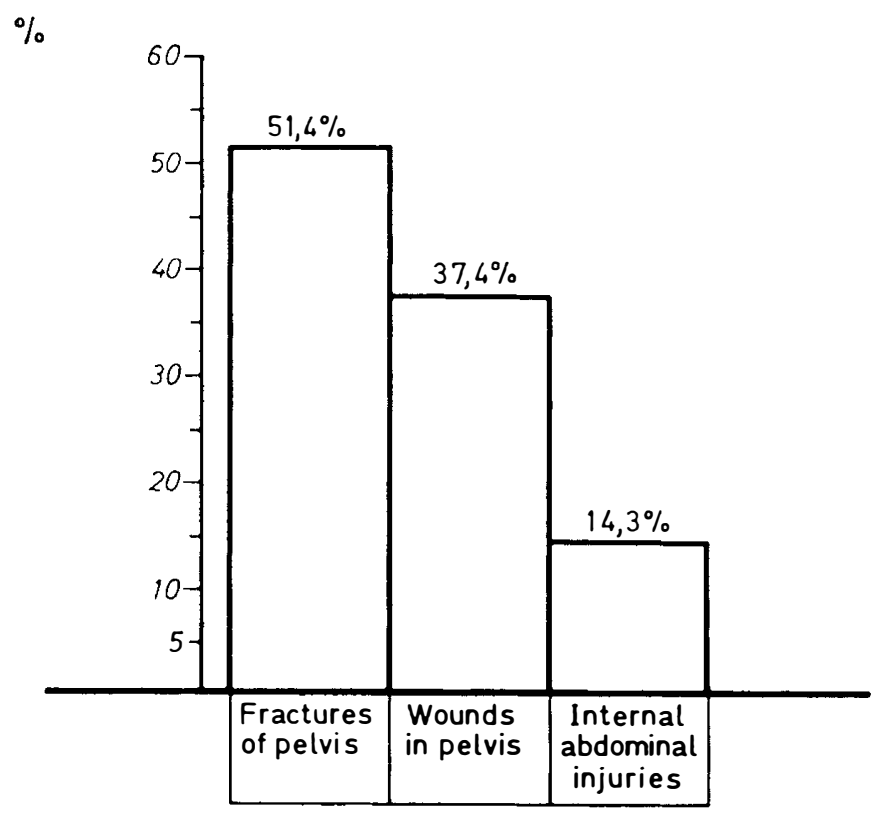

\section{DISCUSSION}

In more than 50 per cent. of all paraplegics, we have to expect associated injuries. Among these, skull injuries occur most frequently. On account of the unconsciousness produced by the involvement of the brain, first aid already presents special problems. Fractures of the ribs call for increased and immediate attention. In hospital a roentgenogram of thorax and lungs should be made as soon as possible. Haemothorax and pneumothorax may decrease the expectation of life considerably; they occasionally develop only due to inappropriate treatment when fractures of the ribs have been overlooked. Fractures of limbs occur quite often and their treatment in the presence of spinal cord injuries, requires special measures in order to avoid pressure sores, stiffening of joints and contractures while the fracture is immobilised. Injuries to the internal organs of the abdomen, however, occur so rarely that operation seems justified only if all signs indicate bleeding in the abdomen or infection of the peritoneum. An early paralytic ileus alone is not a sufficient reason for a laparotomy.

Injuries to the abdomen in paraplegics are particularly difficult to diagnose. Especially in the acute stage, the defensive reflexes reacting to pain do not work in the paralysed region. But the evidence of free air in two-way X-rays of the abdominal area indicates a perforation. Lately attention has been drawn to the 
TABLE IX

Types of accidents and lypical associated injuries

\begin{tabular}{|c|c|c|c|c|c|c|c|c|c|}
\hline & 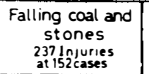 & $\begin{array}{l}\text { Crushes } \\
\text { 69, tijuries } \\
\text { at 33riases }\end{array}$ & $\begin{array}{c}\text { Fall s } \\
92 \text { Injuries } \\
\text { at } 26 \text { cases }\end{array}$ & 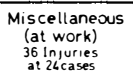 & $\begin{array}{c}\text { Car } \\
45 \text { Injuries } \\
\text { at } 26 \text { cases }\end{array}$ & $\begin{array}{l}\text { Two-wheel } \\
\text { 18 Injurres } \\
\text { at I1 icases }\end{array}$ & $\begin{array}{l}\text { Pedestrian } \\
\text { is injurres } \\
\text { at byases }\end{array}$ & $\begin{array}{l}\text { Domestic } \\
23 \text { tnjuries } \\
\text { atticases }\end{array}$ & $\begin{array}{l}\text { Sport } \\
\text { 7Injuries } \\
\text { at 7cases }\end{array}$ \\
\hline Spinal processes & $30,8 \%$ & $26,1 \%$ & $13,0 \%$ & $22.2 \%$ & $17,8 \%$ & $11,1 \%$ & $6,2 \%$ & $21,7 \%$ & $14,3 \%$ \\
\hline Thorax & $21,1 \%$ & $29,0 \%$ & $13,0 \%$ & $19,4 \%$ & $17,8 \%$ & $16,7 \%$ & $18,8 \%$ & $17.4 \%$ & - \\
\hline Skull and brain & $18,5 \%$ & $8,7 \%$ & $40,3 \%$ & $30,6 \%$ & $46,6 \%$ & $50,0 \%$ & $37.5 \%$ & $30.5 \%$ & $85.7 \%$ \\
\hline Lower limbs & $15,2 \%$ & $11,6 \%$ & $17.4 \%$ & $11,1 \%$ & $6.7 \%$ & $5,5 \%$ & $25.0 \%$ & $8,7 \%$ & - \\
\hline Upper limbs & $9,3 \%$ & $11,6 \%$ & $13,0 \%$ & $5,6 \%$ & $8.9 \%$ & $16,7 \%$ & - & $13,0 \%$ & - \\
\hline Abdomen-Pelvis & $5,1 \%$ & $13.0 \%$ & $3,3 \%$ & $11,1 \%$ & $2,2 \%$ & . & $12,5 \%$ & $8,7 \%$ & - \\
\hline
\end{tabular}

$\%$

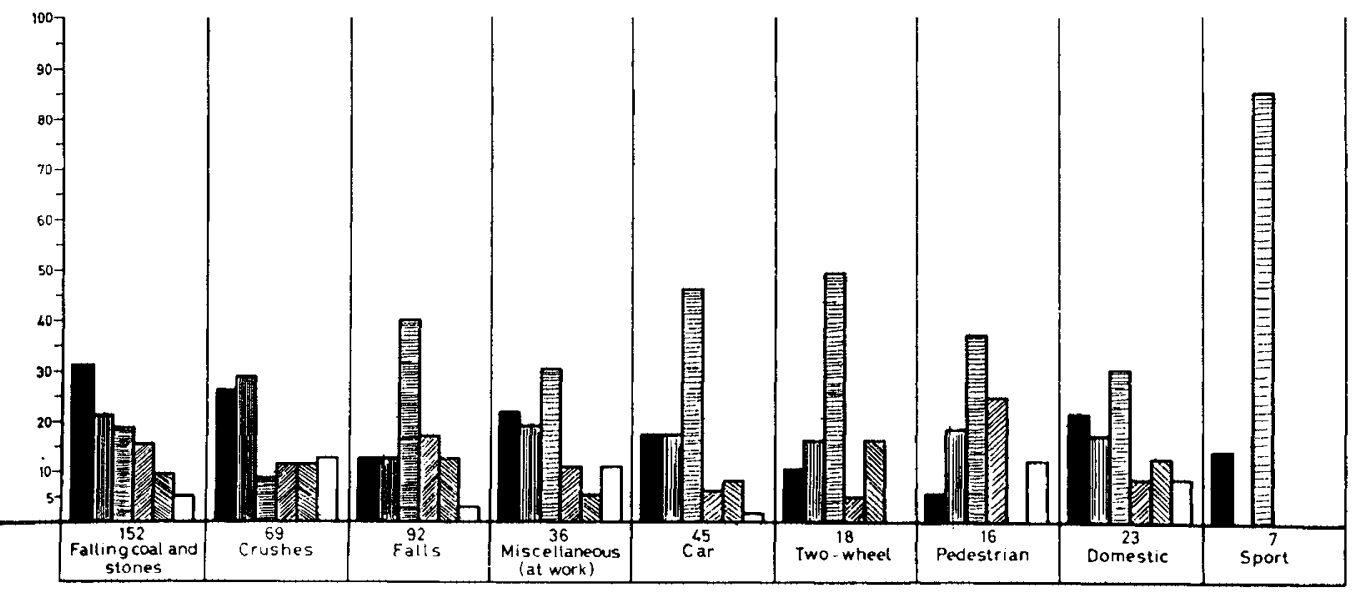

Spinal processes 四 ihorax

目 skull and brain

Lower limbs

$\mathbb{Q}$ upper limbs

Dabdomen - Pelvis 
TABle $\mathrm{X}$

Iypes of accidents and level of spinal cord injury

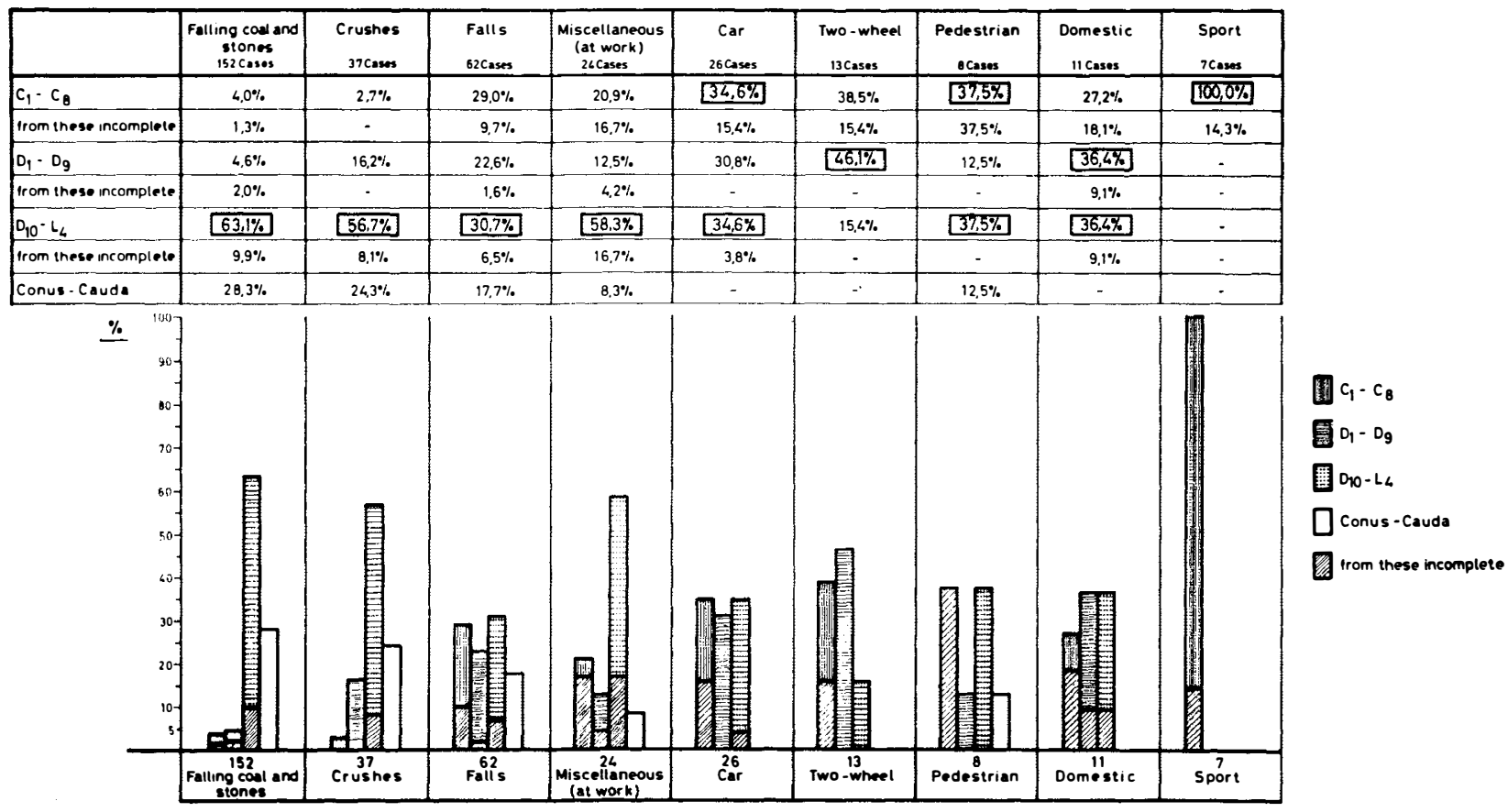


'paracentesis' as a means of diagnosis (G. Schlag). It is meant to diagnose intraabdominal bleedings by inserting a Redon-tube into the abdominal cavity by way of a trocar. Under this special aspect this method may probably be justified. In the presence of an ileus, however, it should not be applied in order to avoid the danger of injuring the intestines.

The range of possible associated injuries clearly shows that in most cases one cannot agree with the view that X-ray examination of the acutely injured paraplegic can be postponed to a later date without great danger to the patient. This is only justified in the presence of shock, when any further strain has to be avoided. Of the 595 patients with or without associated injuries which we have screened, only 95 ( 16 per cent.) were in shock at the time of admission. case:

The urgency of X-ray examination may be exemplified by the following

A 36-year-old miner was buried by coal on 14 October 1966. On admission to the hospital where he was first treated, unconsciousness had subsided, but it was found that he had multiple bilateral fractures of ribs, fractures of the left leg and astragalus, of the second and fifth lumbar vertebrae, of the transverse processes at the first and fifth left lumbar vertebrae, a complete paraplegia at $\mathrm{LI}_{\mathrm{I}}$, and that the patient was in a state of shock. On I5 October I 966 he was transferred to our hospital by helicopter. After removing the plaster jacket and a cast for the left leg which had been applied for transport, we immediately made an X-ray of the lungs of this patient who was extremely cyanosed and weakened. The radiograph showed signs of a rupture of the diaphragm on the left side (fig I) The diagnosis was verified by Barium-meal (fig. 2). Two hours after admission we opened the thorax and found that stomach, spleen, transverse colon and greater omentum had moved through a tear of $18-\mathrm{cm}$. length into the thoracic cavity. After replacing the entrails the rupture of the diaphragm was closed. On 25 October I966 a haemothorax developed on the right side which was then sucked off. The fracture of the left leg was fixed with a condyle plate (fig. $3 \mathrm{~A}-\mathrm{C}$ ) on 28 October 1966, after the leg had been immobilised up to this point on a plaster-L-splint which had been redressed daily. On 29 October 1966 the patient developed another haemothorax which was again sucked off. Today the patient is well and is being fully rehabilitated. It is likely that if we had postponed X-ray examination of the critically weak patient, the rupture of the diaphragm would have been discovered too late. Strangulation with all its consequences would have been unavoidable.

\section{CONCLUSION}

The frequency of associated injuries in paraplegics should cause us to stress the urgency for taking into account the possibility of such injuries already during first aid. Injuries to the skull occur most frequently. The admitting doctor has to examine the acutely injured very thoroughly for associated injuries, in particular the thorax. The clinical findings have to be supplemented as soon as possible by X-ray examinations. Sometimes, however, a haemothorax does not develop until a few days after the accident. There is hardly a type of accident which could not result in associated thoracic injuries. The danger of life to the acutely injured in spinal shock is considerably increased by impaired breathing. Every associated injury requires certain deviations from the orthodox methods of treatment, since paraplegia holds specific additional risks uncommon in nonparalysed patients, such as pressure sores, contractures, limited or suspended thoracic respiration in cervical lesions, etc. 


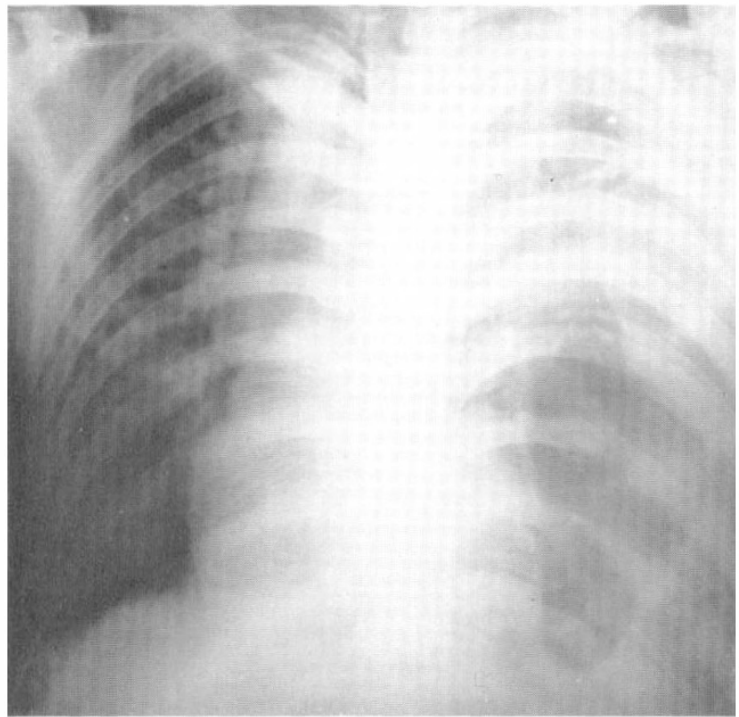

FIG. I

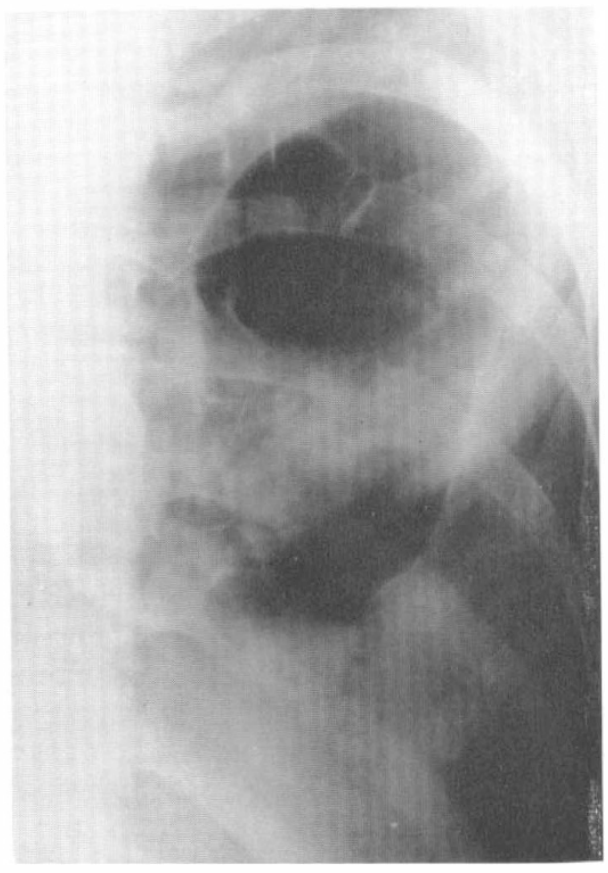

FIG. 2 

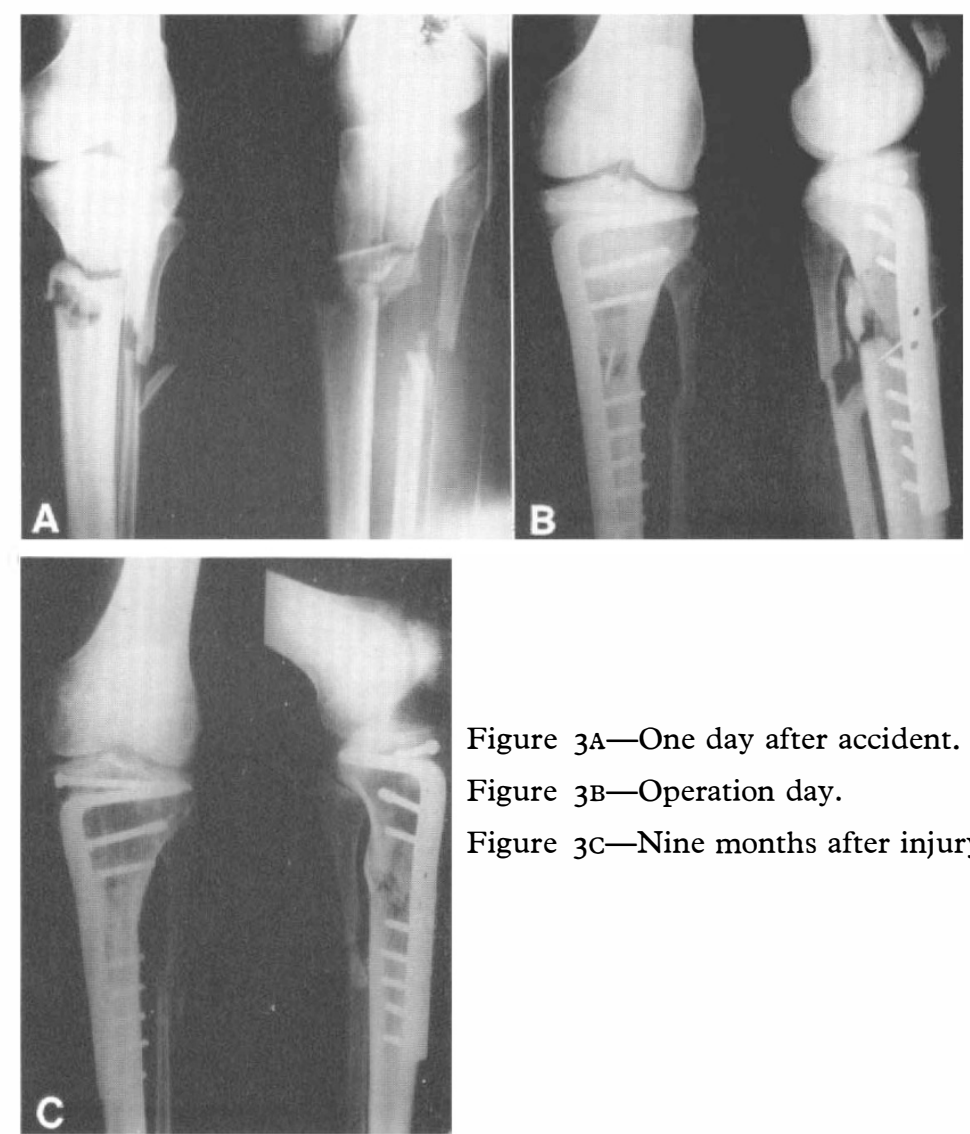

Figure $3 \mathrm{~A}-$ One day after accident.

Figure $3 \mathrm{~B}-$ Operation day.

Figure $3 \mathrm{C}-$ Nine months after injury.

The questions put forward at the beginning of this paper may be answered as follows:

I. Associated injuries in paraplegia are frequent; they are found in $57^{\cdot} \mathrm{I}$ per cent. of all paraplegics.

2. Falling coal or stone, falls and crushes are the most frequent causes of paraplegia.

3. In patients buried by coal or stone the most frequent type of associated injury is fractures of the vertebral processes; in crushes it is chest injuries. In any other type of accident, it is the skull which is affected most frequently.

4. The following injuries are particularly frequent:

skull: concussion of the brain.

thorax: fractures of the ribs.

upper limb: fractures of the forearm.

lower limb: fractures of the leg.

pelvic region: fractures of the pelvis. 
Incidence of accidents in 100 non-paraplegics and in 340 paraplegics with mul tiple injuries

$\%$

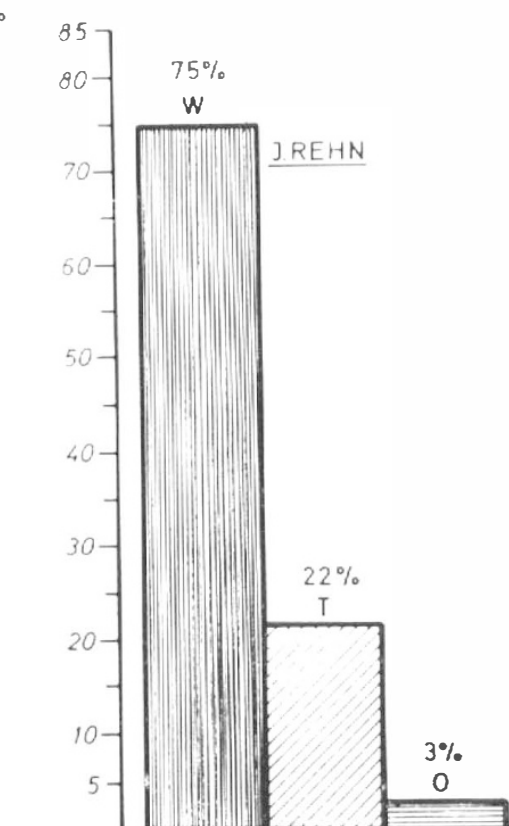

$81 \%$

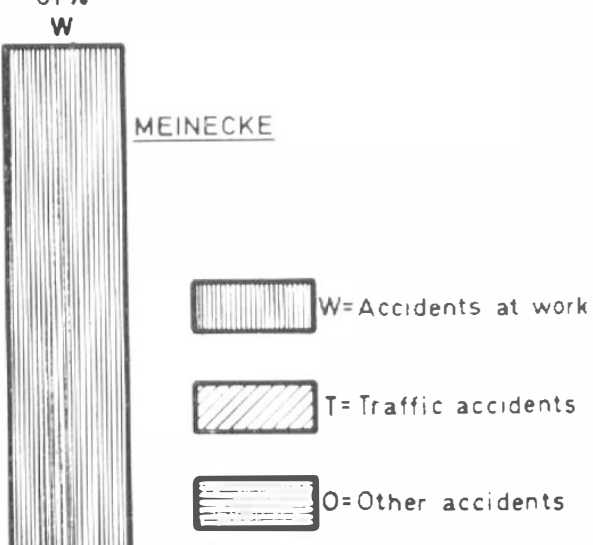

$\%$

T

$5 \%$

\section{TABLE XII}

Incidence of specific injuries in 100 non-paraplegics and in 340 paraplegics with multiple injuries

$\%$

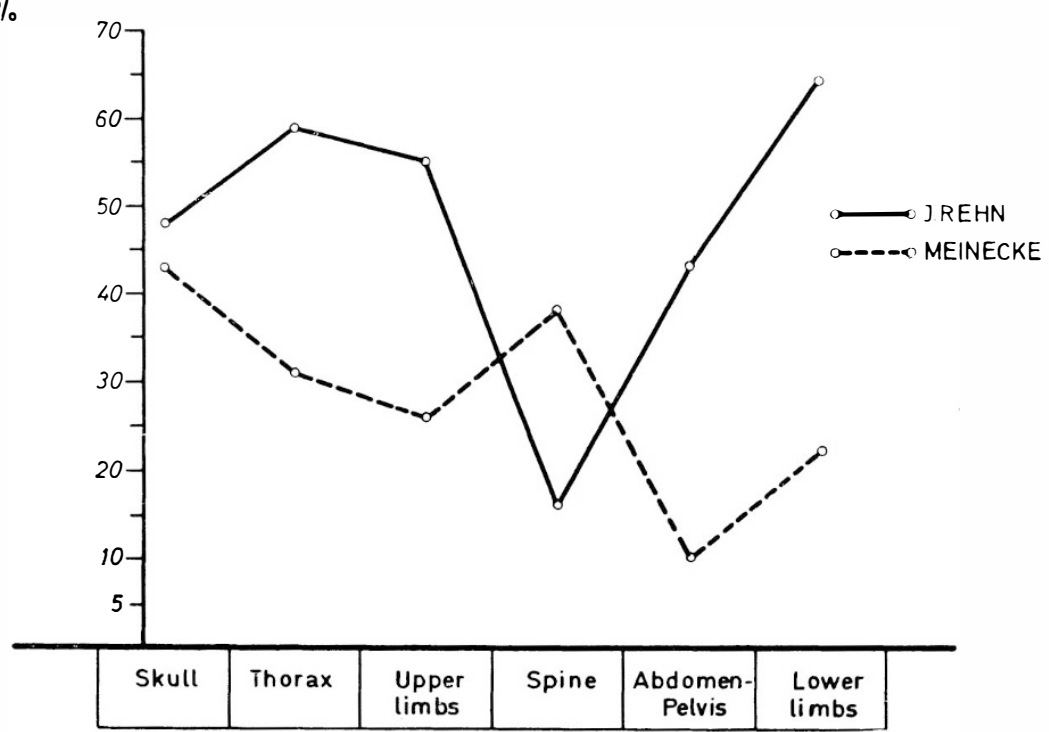


Jörg Rehn presented a material of Ioo severe and selected cases with multiple injuries which were treated from 1962 to 1965 . In conclusion we want to compare these cases under two aspects with the material we reviewed ourselves.

I. Incidence of accidents: here, the percentage of accidents at work is higher in paraplegics (Table XI). This is easily explained by the fact that until a few years ago we admitted only professional accidents.

2. Incidence of specific injuries: in both reviews we find an almost even percentage of injuries to the skull. In every other respect, however, the two curves differ widely. Certainly the reason for this discrepancy lies partly in the aspects under which these cases were compiled. The first group was selected solely according to the degree of injury, while the second group comprised only cases with injuries of the spinal cord. We nonetheless thought that a comparison would be worthwhile as it shows distinct differences.

\title{
REFERENCES
}

REHN, JöRg (1966). Probleme der Diagnostik und des schweren Unfalls. Hft. Unfallheilk, 87, I I I-I I 7.

SchlAG, G. (1967). Abdominelle Katheterparazentese beim stumpfen Bauchtrauma. Chirurgie, 2, 17-20.

\section{ASSOCIATED FRACTURES OF THE LIMBS IN TRAUMATIC PARAPLEGIA AND TETRAPLEGIA}

\author{
By Jean Bénassy, M.D. (Paris) \\ Hopital Poincaré, Garches
}

WE will relate only, and briefly, our cases of traumatic paraplegia and tetraplegia with associated fractures of the paralysed limbs. Amongst our 250 most recent cases 16 patients, with important fractures have been studied ( 2 tetraplegics and I4 paraplegics). In all there were 28 fractures involving femur (I0), hip (5), ankle (5), os calcis and astragalus (8). One of the patients, a paraplegic below $\mathrm{T}_{4}$, with a severe injury to the chest, had 5 associated fractures.

It could appear that the lower the level of the spinal cord lesion the higher the percentage of the fractures of the lower limbs, the site of these becoming correspondingly lower. In fact, the two tetraplegic cases had their fractures high up in the femur, while the cases of lumbar fractures were frequently associated with bilateral fractures of the os calcis.

Prognosis.-On the whole quite good, which is one of the rare optimistic chapters in paraplegia because:

(I) pain being absent an anaesthetic is not necessary.

(2) flaccidity, in the early days, seems to allow easy reduction.

(3) later on, the absence of pain makes results tolerable, which, in particular for the os calcis, would have been quite impossible for normal patients. 